\title{
O portefólio na formação e avaliação profissional de professores*
}

\author{
João Silva \\ Nicole Rebelo \\ Patrícia Mendes \\ Adelinda Candeias \\ Universidade de Évora
}

\author{
Correspondência: \\ João Silva \\ CIEP - Centro de Investigação \\ em Educação e Psicologia \\ Universidade de Évora \\ Apartado 94 \\ 7002-554 - Évora \\ E-mail: joao.pontevel@gmail.com
}

\footnotetext{
* Trabalho apresentado em formato de comunicação na XIV Conferência Internacional de Avaliação Psicológica: Formas e Contextos, Campinas (SP), Brasil, de 29 jul. 2009 a 1 ago. 2009.
}

\section{Resumo}

A área da avaliação e formação de professores está em constante renovação, incapaz de abarcar todos os conteúdos relevantes de um modo completo, deixando (in)satisfeitos avaliados e avaliadores (ou seja, os docentes). Sendo uma área bastante complexa, o método de avaliação por portefólios tem assumido uma importância vital nos últimos anos, tido como uma ferramenta que possibilita a avaliação de vários domínios. Para além disso, permite o acompanhamento da evolução do desenvolvimento pessoal e profissional enquanto medida qualitativa de avaliação, mas também é utilizado para discriminar professores excelentes de professores "satisfatórios" no processo de progressão na carreira. Os portefólios são ainda utilizados como base para as entrevistas de emprego e como meio de apresentação do indivíduo em novos contextos de trabalho. Neste sentido, procurámos estudar a validade e a utilidade desta ferramenta de avaliação de professores na área da formação profissional, comprovando a sua aplicabilidade e as respectivas vantagens/desvantagens. Através da revisão bibliográfica de vários estudos desenvolvidos até o momento, salienta-se a importância do portefólio como instrumento de avaliação de docentes em início de carreira (visando a sua evolução) e sua complementaridade com outros métodos. Assim, atingimos um modelo de avaliação mais completo, individualizado, eficaz no desenvolvimento e avaliação de competências, acessível a toda a comunidade escolar e não circunscrito a um determinado período ou momento, mas valorizando a vida profissional dos docentes.

\section{Palavras-chave}

Portefólio - Aprendizagem - Desenvolvimento - Competências Avaliação de professores. 


\title{
The portfolio in teacher education and professional evaluation*
}

\author{
João Silva \\ Nicole Rebelo \\ Patrícia Mendes \\ Adelinda Candeias \\ University of Évora
}

\author{
Contact: \\ João Silva \\ CIEP - Centro de Investigação em \\ Educação e Psicologia \\ Universidade de Évora \\ Apartado 94 \\ 7002-554 - Évora \\ E-mail: joao.pontevel@gmail.com \\ * This work was presented as a \\ communication at the 14th Inter- \\ national Conference on Psychologi- \\ cal Evaluation: Forms and Contexts, \\ held in Campinas (SP), Brazil, from \\ July 29th to August 1st, 2009.
}

\begin{abstract}
The area of teacher education and evaluation is in constant renovation, incapable of encompassing all relevant contents in a complete manner, leaving (dis)satisfied both evaluated and evaluators (that is, teachers). In such complex area, the method of evaluation by portfolio has assumed a vital importance in recent years, regarded as it is as a tool that allows the evaluation of various domains. Moreover, it makes it possible to follow the evolution of personal and professional development as a qualitative measure for evaluation, and can also be used to separate excellent teachers from "satisfactory" ones in the process of career progression. Portfolios are also used as basis for job interviews and as a means of presentation of the individual in new job situations. In this sense, we investigated the validity and usefulness of this tool for teacher evaluation in the area of professional education, demonstrating its applicability and respective advantages and disadvantages. Through a bibliographical survey of several published studies, the importance of the portfolio is highlighted as an instrument for the evaluation of teachers at the beginning of their careers (aiming at their evolution) and its complementarity with respect to other methods. We have, therefore, achieved a more complete evaluation model, more individualized and efficient in the development and evaluation of competences, accessible to all education community, and not restricted to a given period or moment, but valuing the professional life of teachers.
\end{abstract}

\section{Keywords}

Portfolio - Learning - Development - Competences - Teacher evaluation. 


\section{Introdução}

A sociedade contemporânea da globalização e da interdependência, do conhecimento e da inovação, não para de evoluir ao ritmo alucinante das diversas transformações que se manifestam e operam nos vários setores e campos de ação social, com repercussões ao nível da ciência e da produção de conhecimento científico. Assim, torna-se imprescindível que as instituições abarquem esta nova realidade e aprovem os seus consequentes desafios, pois a instituição educativa não deve se alhear de todas estas metamorfoses (LEITÃo; ALARCÃO, 2006).

Nesta sociedade dinâmica, pautada pelo conhecimento científico e tecnológico e caracterizada pela necessidade constante de atualização de competências e pelo valor atribuído às decisões/escolhas individuais e participação social, a carreira profissional inclui a vida, a aprendizagem e o trabalho, bem como a sua indissociável relação (PEREIRA; CRUZ; LUCENA, 2006). Situada numa escola que se quer em permanente mudança e envolta numa profissão “obrigada” a estar em constante (re) construção, a formação de professores mantém-se como alvo de discussão, problematização e várias críticas (FORTE, 2005). Neste sentido, para além da formação inicial de professores - onde as universidades e os centros universitários têm uma grande responsabilidade social, com a instrução docente e a educação do nosso país (ALMEIDA; BIAJONE, 2007) - a formação contínua é o grande motor deste processo. Esta última é um fator essencial da profissão docente por ter em si a possibilidade de articulação com a formação inicial e a revisão/ aperfeiçoamento de um conjunto de atitudes e comportamentos diante do conhecimento profissional e do conhecimento do mundo em geral (RIBAS; MARTINS; LUPORINI, 2001).

É indiscutível que tanto o processo de instrução e de ensino-aprendizagem como de avaliação fazem parte do quotidiano escolar. Porém, o que se discute é como avaliar os diferentes atores do cenário educativo (BIAZZI,
2006), neste caso concreto, os professores. Até há bem pouco tempo, a responsabilidade pela avaliação docente cabia principalmente ao diretor da escola, que, em conjunto com uma pequena comissão, avaliava um relatório crítico dos docentes e lhes atribuía a respetiva classificação. As crescentes exigências colocadas sobre os professores levaram a que este processo fosse frequentemente percebido como um exercício que de pouco ou nada servia para melhorar e inovar o ensino e as práticas educativas (PETERSON, 2000). Mais, a avaliação de desempenho docente transformara-se numa formalidade exigida por determinadas leis e políticas, um processo altamente moroso e de questionável valor (SAWYER, 2001), realizado anualmente, através da observação de um determinado "acontecimento", consoante os requisitos escolares ou estatais (ZEPEDA, 2002). Posteriormente, a comunicação dos resultados seria feita através de um monólogo ou de uma breve palestra, proferida pelo avaliador, onde o docente assumiria um papel passivo (DANIELSON; MCGREAL, 2000). Desse modo, maior é o tempo e os recursos que os professores despendem para pensar, refletir e discutir com os outros o seu crescimento profissional e as possibilidades de aperfeiçoamento da sua performance (ATTINELLO; LARE; WATERS, 2006).

Aplicar o tradicional método clínico de avaliação de "tamanho único" (standard) para todos os docentes, independentemente da sua experiência ou talento, faz pouco sentido e resulta em desperdício de tempo precioso, que podia ser utilizado de forma mais eficaz para ajudar os professores a crescerem e a melhorarem as suas práticas. Os docentes com diferentes habilidades e experiências têm diversas necessidades no que se refere ao desenvolvimento profissional. Dessa forma, se o verdadeiro objetivo da avaliação consiste, em última análise, na promoção da qualidade de ensino, os educadores devem considerar os méritos através de formas alternativas de avaliação. Informações relacionadas com as práticas de avaliação docente como um meio para melhorar a instrução 
serão altamente benéficas para todos aqueles que desenvolvem programas de preparação para professores e para aqueles que os avaliam (ATTINELL0; LARE; WATERS, 2006).

\section{A avaliação dos professores centrada nas competências}

Com as alterações nos processos de avaliar e certificar professores, têm-se procurado também novos métodos de avaliação. 0 objetivo é criar um suporte de desenvolvimento profissional desta classe, enfatizando o processo de aprendizagem contínua de modo refletido (SCHOEN, 1983, citado por IMHOF; PICARD; 2009). Com esse intuito, o clima corrente das constantes reformas educativas desencadeou um interesse renovado pela forma como o desempenho profissional dos professores é avaliado, passando pela modificação ou abandono dos procedimentos mais tradicionais (ATTINELLO; LARE; WATERS, 2006). Este tipo de formação não se resume apenas à oportunidade de reciclagem de conhecimentos, mas passa pela reformulação de atitudes e adoção de uma postura que permita o uso do conhecimento e dos conceitos de forma diferenciada, consciente e produtiva (RIBAS et al., 2001).

Neste contexto, em paralelo com o movimento direcionado para conceptualizar alternativas na avaliação dos alunos (BIRENBAUM, 1996), o portefólio de ensino profissional tem-se destacado por ser um método flexível, conciso e autêntico para desenvolver e avaliar competências de ensino individuais (DARLING-HAMMOND; SNYDER, 2000). De facto, nos últimos anos a questão da avaliação de competências tornou-se crucial para a profissão docente. Conceptualmente é aceite que a competência é um conceito relacional, reunindo características pessoais, conhecimentos, habilidades e atitudes básicas para a prática das diferentes tarefas profissionais no seu contexto (VAN DER SCHAAF; STOKKING, 2008). Mais especificamente, a performance no ensino está diretamente relacionada com supervisão, educação, capacidade de transferência e gestão da sala de aula, ou seja, com competências de ensino. Exemplos destas últimas são a capacidade de trabalhar de forma independente, de planear e refletir e ser capaz de modificar o próprio comportamento. Adicionalmente, aos professores pedem-se ainda as chamadas competências de parceria, ligadas ao relacionamento com os pais e encarregados de educação, colegas e diretores da escola, bem como com todos os restantes agentes educativos (MEEUS; PETEGEM; ENGELS, 2009).

$\mathrm{Na}$ formação de professores, os portefólios profissionais e individuais são usados para avaliar as competências necessárias para realizar tarefas profissionais de ensino (MEEUS; PETEGEM; ENGELS, 2009) e funcionam como método de seleção, contratação, avaliação e promoção na carreira docente (GREEN; SMYSER, 1995).

Posto isto, pretendemos compreender o lugar do portefólio na formação profissional dos professores, baseando-nos no crescente corpo de investigação nesta área, que contribui para a sua compreensão como uma ferramenta de aprendizagem e avaliação, extremamente útil para o estudo do desenvolvimento profissional destes indivíduos (HAUGE, 2006). Este artigo pretende realizar uma revisão de literatura sobre a temática dos portefólios na formação e avaliação dos professores, centrando-se na avaliação por competências (valorizando os processos formativos), na caracterização e nas vantagens/desvantagens que esta metodologia apresenta. Procuramos articular diversos contributos bibliográficos, principalmente em língua inglesa, bem como postular uma breve perspectiva crítica sobre essa mesma produção teórica, especialmente no contexto europeu e particularmente o português, pois são estes os nossos contextos de referência.

\section{Do conceito de portefólio à sua validade}

Atualmente, o uso do portefólio é uma prática comum para vários fins (MEEUS; PETEGEM; ENGELS, 2009; TUCKER; STRONGE; 
GAREIS, 2002). Na educação, podem ser aplicados ou adotados por e em diversos contextos: nas escolas, como forma de autoapresentação e divulgação; pelos alunos, como estratégia de animar e encorajar a aprendizagem e/ou a avaliação; e pelos docentes, como instrumento/ processo de desenvolvimento pessoal e/ou avaliação de desempenho (GOMES, 2008).

Todavia, ainda subsistem algumas dúvidas sobre a validade desta ferramenta, e uns defendem a sua utilização e a consideram um instrumento muito útil, enquanto outros mantêm inúmeras reservas quanto ao seu uso para os referidos objetivos. 0 centro da discórdia reside, principalmente, na confusão que ainda permanece sobre o conceito de portefólio, pois não existe um, mas sim vários tipos de portefólios, cujas características variam de acordo com os seus objetivos e com o formato próprio que assumem (MEEUS; PETEGEM; ENGELS, 2009). Nesse sentido, muitas têm sido as investigações que exploram e estudam essa ferramenta, embora as diferenças mais relevantes entre os vários portefólios, no que respeita a características e objetivos, dificultem a extração de conclusões acerca do seu valor (MANSVELDER-LONGAYROUX; BEIJARD; VERLOOP, 2007). Para tentar clarificar um pouco esta questão, atentemos para etimologia da palavra portfolio: port, na sua origem latina, significa transportar/levar, assumindo neste contexto a possibilidade de manuseio e gestão de competências, enquanto folio, de origem latina (foglio), significa folha, referindo-se a todo um conjunto de artefactos (documentos, fotos, vídeos, CDs etc.) que mostram competências e exibem no portefólio o seu desenvolvimento, numa forma de comunicar aos outros os seus resultados (PEREIRA et al., 2006).

Na perspectiva de Fryer-Edwards, Pinsky e Robins (2006):

A portfolio is a purposeful collection of evidence gathered by individuals in their roles as learners, recording and reflecting on a learner's progress and achievement in selected domains. (p. 214)
Virando a questão para o contexto educativo, especialmente para o meio escolar, Winsor e Ellefson (1995) defenderam que um portefólio é uma coletânea de produtos autênticos e variados que documentam, de forma refletida, organizada e contínua, o progresso profissional, os objetivos, reforços, práticas pedagógicas, atitudes, comportamentos, talentos, interesses e desenvolvimento ao longo do tempo. Na perspectiva de Lyons (1998), é um processo dinâmico, em que os professores podem ostentar o seu trabalho e crescimento profissional, recolhido e produzido através de cuidadosas reflexões, partilhado com os colegas e estudantes e apresentado/discutido publicamente, na procura de concepções de boa docência.

Por outro lado, para combater a possível discrepância na atribuição de pontuações entre avaliadores e, consequentemente, as possíveis injustiças nas atribuições das notas finais, Meeus, Petegem e Engels (2009) referem que é indispensável seguir algumas regras, iguais para todos - criação de um protocolo de avaliação único; seguir um checklist com os critérios de avaliação a utilizar e dar o mesmo portefólio a avaliar a mais do que um avaliador. Em consequência, Van der Schaaf e Stokking (2008) assumem que, de acordo com os seus resultados, é pré-requisito para uma avaliação válida a existência de uma relação estreita entre o formato do portefólio, a estandardização dos conteúdos, o modelo de classificação, as capacidades dos professores e avaliadores e a finalidade e o contexto da avaliação. Um exemplo prático dos critérios que podem ser utilizados é o que surge no trabalho de Darling (2001), em que cada portefólio seria avaliado como excelente, bom, suficiente ou inaceitável a partir dos seguintes aspectos: coerência e coesão (todos os elementos juntos formam uma forte confırmação do potencial); abrangência (tudo o que era pedido está, de alguma forma, abordado no portefólio); clareza (o objetivo de cada entrada é claro e cuidadosamente concebido); criatividade (a voz do autor e o seu ponto de vista são apresentados 
de forma imaginativa) e potencial comunicativo (na expressão e na forma, o portefólio reflete a experiência vivenciada de forma que possa ser efetivamente partilhada pelos outros).

Para além dessas dimensões, o portefólio pode apresentar duas grandes finalidades: 1) durante o seu processo de construção, contribui significativamente para a aprendizagem, através da autoavaliação, do feedback externo e da reflexão sobre o que foi e como foi aprendido, bem como para a identificação de pontos fortes e fracos e 2) quando finalizado, a sua avaliação permite o acesso à evolução do sujeito durante um vasto período de tempo (TILLEMA, 1998).

\section{Os portefólios na avaliação da formação profissional de professores}

No cenário educativo, a adoção do portefólio tem sido incrivelmente crescente, sendo-lhe reconhecido um enorme potencial para valorizar a aprendizagem, o ensino e a avaliação de práticas (GOMES, 2008). Sua utilização na avaliação docente é um fenómeno relativamente recente (LYONS, 1998) e são ainda poucas as pesquisas realizadas sobre o seu uso neste âmbito. Inicialmente, ele foi introduzido para avaliar aspectos relacionados com a autenticidade das tarefas, a aprendizagem ao longo do tempo e a aplicação de conhecimentos. Atualmente, esta ferramenta é também muito utilizada devido à autenticidade e complexidade das tarefas propostas, por requerer o envolvimento ativo dos participantes, promover o espírito reflexivo e a autoavaliação, bem como facilitar os processos de interação colaborativa (MCLAUGHLIN; VOGT, 1998), fundamentais para o sucesso do processo.

Segundo o movimento construtivista, para além da aquisição de estratégias de aprendizagem direcionadas para a avaliação dos alunos, é igualmente importante potencializar estas estratégias para os professores. Assim, talvez possamos defender que os mesmos princípios aplicados ao uso do portefólio na avaliação estudantil também possam ser úteis e valiosos na avaliação do desempenho dos professores (ATTINELLO; LARE; WATERS, 2006), embora com os devidos ajustes e adaptações.

Uma importante e possível forma de qualificar os portefólios é pelas competências e objetivos que visam (MEEUS; PETEGEM; ENGELS, 2009), podendo constituir, por exemplo, uma estratégia de estimulação para a aprendizagem, um instrumento de avaliação profissional ou académico, um argumento na procura da sua utilidade, um meio de promoção de um produto ou um testemunho de desenvolvimento pessoal ou profissional (GOMES, 2008). Zeichner e Wray (2001) categorizaram este instrumento em três classes: 1. portefólio de aprendizagem (com o objetivo de envolver os professores no questionamento do seu ensino e documentar o crescimento do mesmo ao longo do tempo); 2. portefólio credencial (procura avaliar a perspectiva dos professores acerca da forma como obtiveram a licença para ensinar); e 3. portefólio profissional (organizado para uso na profissão, compreendendo uma amostra de documentos representativos do melhor trabalho). Outro esquema classificativo dos portefólios foi proposto por Smith e Tillema (2003), identificando quatro tipos nos programas de educação profissional: 1. portefólio dossier (utilizado para recolha de trabalho para fins de seleção ou promoção numa profissão ou programa); 2. portefólio de treino (necessário para reunir todos os esforços e trabalho conseguido durante um programa; é representativo do trabalho que os estudantes tiveram ao longo do mesmo); 3. portefólio reflexivo (constitui uma reunião de trabalho intencional e pessoal para ser apresentado para promoção e admissão, para além do estudo); e 4. portefólio de desenvolvimento pessoal (inclui uma avaliação pessoal e considera o progresso profissional ao longo do tempo).

Noutra perspectiva, Wolf, Lichtenstein e Stevenson (1997) distinguiram entre portefólios de avaliação e portefólios de desenvolvimento profissional. Os primeiros são utilizados 
para avaliar a performance de ensino e os segundos focam-se no processo de aprendizagem e avaliam as competências de aprendizagem. Nos de avaliação esperamos encontrar apenas exemplos dos melhores desempenhos dos professores, enquanto nos de desenvolvimento profissional é requerido que estes contenham igualmente as suas piores performances, pois assim podem ser melhoradas. Dessa forma, podemos afirmar que os portefólios dos professores podem avaliar o modo como estes aprendem a ensinar e o modo como aprendem a aprender (MEEUS; PETEGEM; ENGELS, 2009).

Em todo o caso, não só os portefólios individuais podem ser importantes para o crescimento profissional dos professores, mas também o denominado portefólio de escola, em que professores e direção da escola trabalham de forma colaborativa na comprovação daquilo que é o bom ensino e as boas escolas. Este processo mexe não apenas com a vida contínua da escola, mas também com o contínuo crescimento dos indivíduos presentes nesse contexto (CRAIG, 2003) (se o portefólio é um documento inacabado, também a escola deve ser analisada longitudinal e episodicamente, a fim de se averiguar em que grau as opiniões sobre o bom ensino e as boas escolas são refletidas nas ações coletivas e individuais).

\section{A construção e o desenvolvimento do portefólio dos professores}

Desenvolver um portefólio é um processo complexo, interativo e cíclico que inclui uma ou mais fases de planeamento, desenvolvimento, avaliação e revisão (VAN DER SCHAAF; STOKKING, 2008). Na elaboração de um portefólio profissional, é importante descrever e comprovar aspectos como competências de pensamento reflexivo; ligação e empenho ao desenvolvimento profissional; competências colaborativas e de instrução aos outros (alunos e colegas); competências de organização e controlo da sala de aula; filosofia educativa e objetivos de ensino; conteúdos educativos e competências para a sua transmissão, bem como experiências de trabalho anteriores (SALEND, 2001).

Estruturalmente, essa ferramenta deve ser iniciada com um índice, uma pequena introdução de apresentação do seu construtor e do seu background, seguida de uma explicação do(s) objetivo(s), conteúdos e toda a restante organização das várias tarefas constituintes do portefólio (SALEND, 2001). Os diversos documentos são inseridos progressivamente (AZCÁRATE; CARDEÑOSO; SERRADÓ 2005), datados (SANTOS, 2005), e, visto que o principal objetivo é permitir uma aprendizagem autêntica em vários contextos, cada indivíduo deverá ter a oportunidade de decidir individualmente quais as atividades de ensino a incluir no seu portefólio (MEEUS; PETEGEM; ENGELS, 2009). Todavia, uma atividade pode ser mais tarde substituída por outra, desde que justificada adequadamente a razão da substituição - habitualmente essa troca não se faz porque a pessoa considera pobres as suas realizações, mas porque surgiu algo mais relevante para a aprendizagem (SANTOS, 2005).

Para além disso, cada um dos diferentes documentos será acompanhado de uma reflexão pessoal, ostentando o significado que aquele trabalho teve para aquela pessoa. No fim deverá ser incluída uma reflexão global, valorizando o trabalho desenvolvido e a contribuição deste para a aprendizagem e para o exercício da docência (SANTOS, 2005). Nessa lógica, o portefólio é uma prática escolar refletida e consciente, orientada para objetivos e estruturada pelo pensamento. Tal como a reflexão, o planeamento é facilmente avaliado através do portefólio - o plano de aprendizagem pessoal deve ser realista, tão compreensivo quanto possível, utilizado de forma flexível e suscetível de sofrer alterações sempre que necessário (MEEUS; PETEGEM; ENGELS, 2009).

Os portefólios são ainda uma boa forma para guiar o modo como os professores orientam as suas tarefas e exercícios de ensino e aprendizagem, para aceder às aprendizagens dos seus alunos e a alterar a sua prática 
sempre que necessário. Perante este cenário, os docentes têm um olhar positivo sobre esta nova ferramenta, dado que ela os estimula a examinar criticamente o seu método de ensino e a repensar as suas decisões diárias, principalmente as tomadas na sala de aula (PECHEONE et al., 2005). Especificamente na formação inicial de professores, a preparação do portefólio é uma forma de incluir os futuros professores na análise dos conteúdos do trabalho que realizaram, bem como de fomentar a compreensão daquilo que efetivamente constitui um bom trabalho (DELANDSHERE; ARENS, 2003).

A esse nível, sugerimos a consulta do Handbook on Teacher Portfolios for Evaluation and Professional Development (TUCKER; STRONGE; GAREIS, 2002), uma obra dirigida principalmente a professores ainda inexperientes, para efeitos de avaliação e desenvolvimento profissional. Estruturalmente, ele engloba seis capítulos - 1) aborda o conceito de portefólio, o que tem para oferecer ao docente e como pode ser utilizado; 2) orienta o professor na estrutura e desenvolvimento do portefólio; 3) oferece uma perspectiva mais lata sobre o que considerar na sua implementação; 4) e 5) exploram o seu uso em avaliação e no desenvolvimento profissional e 6) resume aquilo que a comunidade educativa tem vindo a aprender sobre esta ferramenta e a direção que lhe dá. Este trabalho conta ainda com dez apêndices de ferramentas que auxiliam na estruturação, organização e execução do portefólio.

\section{O portefólio num modelo multidi- mensional de avaliação docente}

Como se sabe, avaliar não é uma tarefa simples ou fácil, sobretudo porque este processo deve facultar uma reflexão produtora de mudanças, superações, crescimento e evolução, permitindo que educador e educando procurem novas hipóteses de aprendizagem e desenvolvimento pela progressiva e constante (re)construção de conhecimento. Para além disso, é essencial que a avaliação se vire para a compreensão dos diversos fatores que facilitam/dificultam a construção do conhecimento, permitem a sua reflexão e ajudem a ultrapassar as dificuldades. Não devemos também esquecer que este deve ser um processo justo, que se afaste da simples classificação, mas consinta uma análise efetiva da aprendizagem e a reorganização do processo de ensino, favoreça o pensamento, a crítica e a expressão das ideias (ALBERTINO; SOUZA, 2004).

Chiavenato (2004) critica os métodos de avaliação tradicionais mais utilizados por serem demasiado burocráticos, rotineiros e considerarem as pessoas homogéneas. Para vencer as limitações destes métodos (não discutidos aqui, pois não é o intuito deste artigo), surgem outros que visam a participação do sujeito na avaliação e a potenciação da sua performance (REIFSCHNEIDER, 2008). Especificamente ao nível dos professores, também a avaliação pretende incluir informações de diversas fontes (avaliação 360'), embora o confronto entre administradores e docentes gere conflitos e diferentes processos de avaliação. Para uma eficiente avaliação dos professores, o sistema proposto deverá usar um conjunto complementar de instrumentos de coleta de dados (observação e entrevista) que forneça uma visão global do que está a acontecer dentro e fora da sala de aula (AZCÁRATE; CARDEÑOSO; SERRADÓ, 2005).

0 facto de os professores construírem um portefólio e de complementarmente realizarem alguns exercícios específicos, propostos por cada modelo de avaliação, mostrou ter efeitos positivos nas suas práticas educativas e na autopercepção das suas competências de ensino (PECHEONE et al., 2005). Usar o portefólio como parte de um sistema multidimensional de coleta de informação (incluindo múltiplas visitas à sala de aula, o feedback e o suporte regular do avaliador) faz aumentar a precisão e a abrangência, bem como a fiabilidade da avaliação. Nesta perspectiva, existe uma maior amostragem de provas de desempenho docente a partir de diferentes panoramas (TUCKER et al., 
2003). Por exemplo, as observações regulares completam o "retrato pedagógico" do professor, especificamente ligadas ao contexto de sala de aula e às interações que se estabelecem entre os intervenientes. A utilização da avaliação multidimensional pode dar aos professores as rédeas do seu desenvolvimento profissional, uma vez que eles podem refletir sobre as suas práticas nas aulas, debater com os avaliadores a sua performance, defınir e implementar as mudanças necessárias para a prática. Ainda assim, todas estas mutações serão depois mais evidentes se o processo de acompanhamento dos docentes continuar, testemunhando, em primeira mão e em campo, os vários progressos (ATTINELLO; LARE; WATERS, 2006).

\section{O portefólio na revolução tecnológica}

Os portefólios tradicionais de formato papel evidenciam diversos constrangimentos. Os mais comuns são o desconhecimento das atividades que os seus colegas incluíram nos portefólios, a tendência para a elaboração de diferentes portefólios para cada disciplina ou ano escolar (perdendo-se a continuidade da experiência anterior para a seguinte), o facto de cada estudante organizar o seu portefólio à sua maneira, num trabalho muito solitário (LOVE; MCKEAN; GATHERCOAL, 2004), e o limitado feedback que se estabelece relativamente a eles, circunscrito aos comentários (e classificações) atribuídos pelo professor aos respectivos trabalhos. Para além disso, torna-se complicado partilhar portefólios em papel, pois é preciso que estes sejam transportados e andem "de mão em mão", minorando a qualidade dos intercâmbios (ALVES; GOMES, 2007).

Atendendo a isso, podemos afirmar que as potencialidades dos portefólios na renovação no processo de ensino-aprendizagem se dilatam quando este passa a ser realizado em suporte digital ou, melhor ainda, se se basear na denominada Web (ALVES; GOMES, 2007). De facto, a evolução tecnológica e o surgimento das novas tecnologias da informação e comunicação contribuíram para a criação de modernas formas de construção do portefólio, como a versão digital/eletrónica que providencia novas oportunidades, indisponíveis nos formatos e versões convencionais (PECHEONE et al., 2005; GOMES, 2008).

A elaboração dos portefólios digitais assume um conjunto de características que aparenta ser aliciante. Inicialmente, torna-se possível uma adoção mais integrada de uma abordagem multimédia, sobretudo pela introdução de imagens estáticas, animadas ou vídeos, textos e som e por permitir a inclusão de uma estrutura hipermediática na estruturação das informações, através de hiperligações (internas, entre os vários documentos, ou externas, para recursos da Web). Depois, alguns dos softwares ou aplicações informáticas de construção deste tipo de portefólio permitem que outros sujeitos coloquem os seus contributos e comentários, numa perspectiva de crítica colaborativa para com o trabalho do colega. Este é o caso, por exemplo, dos blogues (G0MES, 2006). Para além disso, estes novos formatos facilitam a ajuda on-line na construção do portefólio através da discussão de aspectos particulares do seu trabalho, onde todos podem questionar e apresentar soluções. Tanto os avaliadores quanto os colegas podem, igualmente, dar feedback enquanto o portefólio está ainda em fase de construção, o que acaba por enriquecer a produção final (PECHEONE et al., 2005). Assim, a construção de portefólios digitais implica o desenvolvimento de uma série de competências, permitindo o desenvolvimento de pensamento crítico e habilidades tecnológicas (LORENZO; ITTELSON, 2005).

Ao nível da avaliação, esses novos portefólios podem ser avaliados off-line ou on-line, e estes últimos possuem uma otimizada e aperfeiçoada visibilidade; facilitam o acesso por parte dos pais, professores e alunos simultaneamente; facilitam e providenciam condições para um melhor e rápido feedback sobre o seu desenvolvimento e conteúdo de 
forma mais eficiente (GOMES, 2008). Eles parecem permitir maior uniformidade na expertise dos candidatos à certificação (PECHEONE et al., 2005).

Por seu lado, os portefólios eletrónicos (também referidos como portefólios digitais ou e-portefólios) permitem um melhor envolvimento dos alunos nos ambientes de aprendizagem, uma melhor organização dos portefólios, o desenvolvimento de competências TIC e uma maior acessibilidade/visibilidade do portefólio. No fim, pode constituir-se uma espécie de "repositório digital" dos portefólios, em que toda a comunidade escolar possa ter acesso aos vários trabalhos (ALVES; GOMES, 2007).

\section{Vantagens e limitações do uso dos portefólios (na avaliação e desenvolvimento profissional dos professores)}

0 portefólio tem sido caracterizado como uma ferramenta promotora da prática reflexiva (BORKO et al., 1997), uma forma de iniciar o diálogo sobre o ensino e aprendizagem, uma prova de sucesso na aprendizagem para ensinar (LOUGHRAN; CORRIGAN, 1995) e um meio para o professor provar a sua aprendizagem e crescimento (ATHANASES, 1994). Para além disso, essa ferramenta espelha o progresso dos esforços individuais ou grupais para a resolução das atividades e o desenvolvimento do conhecimento profissional, podendo facultar evidências sobre o progresso na reflexão, o trabalho realizado por si próprio (MARTINELLO; COOK, 2001) e o respectivo crescimento profissional (ROLHEISER; SCHWARTZ, 2001).

Com o portefólio, os professores podem refletir sobre a sua própria prática (ATTINELLO; LARE; WATERS, 2006), pensar sobre as suas próprias experiências (SANTOS, 2005), levando ao fortalecimento de atitudes de colaboração e de partilha. Um dos ingredientes chave para o sucesso desta ferramenta é a própria oportunidade de discutir com os outros a sua prática (ATTINELLO; LARE; WATERS,
2006). Concretamente, este instrumento facilita aos indivíduos um melhor conhecimento sobre si próprios, a tomada de consciência da sua postura perante o ensino e a aprendizagem e as implicações destes aspectos para a prática docente (CHRISTIANSEN; WALTER, 1986). Tal como os estudos apontam, o uso dos portefólios é uma medida extremamente eficaz da performance dos professores e uma ferramenta de reflexão para mudar e melhorar a prática (ATTINELLO; LARE; WATERS, 2006).

Noutro ângulo de visão, Garrison (1999, citado por GOMES, 2008) reconhece aos portefólios um papel muito importante na identificação de alunos com necessidades no âmbito de oportunidades de aprendizagem, bem como de alunos que necessitem de ajuda específica. De facto, a elaboração deste instrumento permite aos professores estarem mais atentos às necessidades educativas dos seus alunos e pensarem com mais profundidade nas suas crenças e valores, isto é, chegar ao nível da metacognição sobre a sua prática pedagógica (PECHEONE et al., 2005). Para além disso, de acordo com Leal (1997), os momentos de seleção de material para o portefólio constituem uma oportunidade privilegiada de interação entre professores e estudantes, e de comunicação bidirecional entre docentes e seus avaliadores (ATTINELLO; LARE; WATERS, 2006).

Seldin (2004) defende que o acesso aos desafios e às virtudes que um professor retira do recurso ao portefólio pode ajudá-lo no início da articulação, conhecimento e exploração das suas atitudes, pensamentos e crenças sobre a excelência no ensino; a projetar ideias úteis para estabelecer uma filosofia e a partilhar com os outros (estudantes, colegas, administração) os seus valores, preconceitos, crenças e aspirações. Ouellett (2007) acrescenta que ele pode ser valioso para os docentes demonstrarem como estabelecem e expressam as suas prioridades na prática do ensino perante diversas situações.

A possibilidade de monitorização desta ferramenta é provavelmente a sua maior potencialidade. De facto, os produtos 
das diversas atividades e as primeiras versões das reflexões podem ser melhorados, a partir das primeiras avaliações, gerando novos momentos de aprendizagem (TILLEMA, 1998). Como sugerem Attinello, Lare e Waters (2006), os professores sentiram que a avaliação não só era justa, como também eles detinham algum poder e controle sobre o seu desenvolvimento profissional.

Importa ainda salientar alguns riscos e limitações associados ao uso do portefólio na avaliação de professores. Nesse sentido, dado que estes sabem que estão a ser avaliados, é provável que nas reflexões sobre o seu desenvolvimento profissional e suas aprendizagens procurem mostrar que atingiram um determinado patamar em que podem não estar (PECHEONE et al., 2005). As reflexões podem ser uma apresentação das opiniões ou um conjunto de respostas desejáveis para o presumível avaliador, de modo a obter pontuações elevadas (AZCÁRATE; CARDEÑOSO; SERRADÓ, 2005). Dessa forma, pode notar-se uma desproporção entre a qualidade do portefólio e a eficácia no processo de ensino, isto é, o sucesso desta ferramenta de avaliação pode não espelhar aquilo que um determinado professor é verdadeiramente. Ainda assim, concordamos com Attinello, Lare e Waters (2006) quando referem que, apesar de todas as limitações, esta ferramenta funciona como um método de avaliação mais preciso do que uma simples observação.

Um outro aspecto inibidor a ter em conta é o tempo exigido para a realização do portefólio. Tempo para conceber reflexões, tempo para debater ideias com os colegas, tempo para o seu desenvolvimento e, posteriormente, é preciso tempo para que quem tem a missão de rever e avaliar os conteúdos do trabalho possa fazê-lo em condições. Se muitos professores despendem muito tempo no planeamento das suas aulas e na concretização de outras atividades diretamente relacionadas com o ensino em sala de aula, o portefólio passa a ser "mais uma tarefa" a incluir no seu ocupado horário. Por outro lado, os avaliadores têm de encontrar tempo suficiente nas suas agendas para rever o conteúdo do portefólio com os professores e debater alterações no processo de ensino-aprendizagem. A participação, apoio e preocupação destes na elaboração do portefólio é essencial para o seu sucesso. Todavia, apesar de mais morosa do que uma simples observação, esta ferramenta apresenta uma visão mais autêntica sobre a verdadeira performance docente (ATTINELLO; LARE; WATERS, 2006).

Na concretização do portefólio, também nem sempre é fácil aos seus autores refletirem sobre o seu trabalho e a forma como o sentiram. Para resolver esse problema, as interações que se estabelecem, em que cada elemento restante do grupo de trabalho lê a reflexão dos outros e tem hipótese de comentar, favorecem a qualidade do trabalho e a partilha das dificuldades. A coavaliação começa a ser desenvolvida, e no fim o coordenador do grupo deverá ler todos os portefólios, comentá-los e indicar onde é que cada um já chegou e aquilo que precisa melhorar. Para além disso, é importante não tornar itens demasiado triviais ou desvalorizar conteúdos importantes que devem alicerçar o portefólio (SANTOS, 2005).

Darling (2001) realça três dificuldades que podem surgir no processo de construção e validação do portefólio - alguma ansiedade dada a amplitude e a natureza do valor de cada tarefa, a falta de modelos que possam guiar precocemente as diversas etapas e a subjetividade do processo de avaliação. Uma outra dificuldade neste processo, apontada por Santos (2005), é que os avaliados precisam estar claramente envolvidos na sua realização, daí a necessidade de estabelecer uma relação de proximidade entre quem faz e quem avalia. Por outro lado, Azcárate, Cardeñoso e Serradó (2005) argumentam que, para além do portefólio ser uma boa ferramenta para o acompanhamento da evolução profissional, o reduzido espaço de tempo em que decorre o seu desenvolvimento não permite a consolidação de todo o trabalho. 
0 próprio processo de avaliação está sempre sujeito a reformulações, presentes no decorrer do trabalho e não apenas no final.

\section{Discussão}

O portefólio não é simplesmente um acúmulo de peças e produtos, mas sim um desdobramento dos entendimentos pessoais do professor sobre o ensino e aprendizagem, bem como acerca do seu desenvolvimento como um profissional. É uma narrativa que conta uma história coerente das suas experiências de aprendizagem, de onde ressalta o potencial reflexivo das mesmas (DARLING, 2001). 0 seu uso, uma prática suportada pela visão construtivista de aprendizagem, pretende capacitar os professores a assumir o seu cargo e a ter uma voz mais ativa na sua avaliação, demonstrando aos avaliadores o porquê de deverem ser considerados eficazes e competentes (BULLOCK; HAWK, 2001).

São muitos os autores que testemunham a importância do portefólio na sala de aula e nas práticas de ensino. Os portefólios construídos pelos alunos são excelentes documentos de iniciação para a reflexão crítica sobre as práticas dos professores e mesmo para os próprios professores refletirem sobre o que é mais importante no que respeita à aprendizagem dos estudantes ou para discutir as suas práticas e estratégias de ensino (GOMES, 2008). Hauge (2006) o propõe como um valioso suporte para a aprendizagem e desenvolvimento na formação dos professores. Por outro lado, em diversas investigações, a reflexão surge como um ponto fulcral no portefólio, ou seja, tal como defende Korthagen (2001), aprender a refletir sobre experiências vividas ao longo da prática de ensino constitui uma importante componente de muitos cursos de formação de professores. Esta capacidade, mesmo não sendo importante apenas para os docentes, promove a mudança nas práticas de ensino quando as reformas educacionais são introduzidas (GRIFFITHS, 2000). Na realidade, o portefólio tem sido cada vez mais utilizado com um conjunto de técnicas variadas para levar os professores em formação a refletir - discussão entre iguais, escrita de diários, pesquisa ativa na prática docente, avaliação das práticas de ensino com recurso a checklists e questionários, estudos de caso, por exemplo (MANSVELDER-LONGAYROUX; BEIJAARD; VERLOOP, 2007).

Dadas as possíveis dificuldades em elaborar reflexões, os resultados da investigação de Van der Schaaf e Stokking (2008) indicaram que os participantes preferiam colocar nos seus portefólios artefactos e reproduções de informação (vídeos) em detrimento das suas próprias produções (nomeadamente, reflexões). Foram apontadas, pelos sujeitos, algumas razões para tal: 1) as reflexões eram vistas como menos confiáveis; 2) a concretização dessas produções pessoais requeria um investimento de tempo extra por parte dos professores que não cabia dentro da sua rotina de trabalho, ao contrário da estruturação dos materiais já existentes; e 3) é mais fácil avaliar perfis com altas pontuações com elementos mais confiáveis do que perfis que contenham produções pessoais. Estes aspectos são importantes para a construção de um modelo de avaliação sobre o que é um portefólio, que, sendo assim, deveria incluir elementos relevantes aos olhos dos avaliadores (VAN DER SCHAAF; STOKKING, 2008).

No estudo de Santos (2005) com aspirantes a docentes de matemática, levantam-se aspectos fundamentais que mostram a forma como o uso do portefólio difere de metodologias tradicionais de avaliação. Em primeiro lugar, o objeto da avaliação deixou de recair sobre um conhecimento específico, passando para um amplo escopo de informação, enfatizando diferentes tipos de capacidades de nível superior, sobretudo a chamada metacognição. Em segundo lugar, o facto de o processo de construção do portefólio decorrer ao longo do tempo favorece a monitorização da avaliação, especialmente a autoavaliação. Em terceiro lugar, os momentos de interação entre os sujeitos, bem como a oportunidade destes escreverem aquilo que pensam sobre determinados 
assuntos, fortalece as relações de proximidade e permite aos alunos/professores identificarem as suas dificuldades e encontrarem formas de resolvê-las. Por sua vez, para os mais receosos, o portefólio pode ser a verdadeira oportunidade de revelarem todo o seu potencial. Um outro aspecto salientado prende-se ao alto nível de autonomia e responsabilidade que é exigido ao longo de todo o processo. Por fim, o papel ativo assumido pelos participantes no processo de avaliação é fortemente relacionado com o cariz pessoal que o portefólio detém. Sendo um documento no qual os indivíduos revelam muito de si próprios e da sua intimidade, é compreensível que esta ferramenta cresça junto do seu autor e acabe por se tornar se reflexo (SANTOS, 2005).

Os mesmos participantes sentiram que, na construção do portefólio, desenvolveram as suas competências de organização (maior preocupação com as atividades selecionadas para colocar no portefólio, juntamente com as devidas reflexões), escrita (melhoria da escrita dos documentos e o reconhecimento das dificuldades sentidas nesta dimensão, algo que anteriormente não era muito vulgar), argumentação, investigação, autonomia e responsabilidade no processo de aprendizagem, bem como determinadas aptidões ligadas à prática da docência (SANTOS, 2005).

Muitos professores, investigadores e outros agentes educativos olham para os portefólios como uma estratégia de aprendizagem, um instrumento de avaliação e uma importante ferramenta de desenvolvimento profissional dos docentes (ALVES, 2005). Eles devem revelar tanto os produtos como os processos para alcançá-los, demonstrando suas reflexões, seu percurso ao nível investigativo, de seleção, análise, síntese e autonomia, indicadores do caminho de desenvolvimento pessoal (GOMES, 2006). Nesta medida, esta ferramenta é cada vez mais utilizada como parte do desenvolvimento profissional contínuo, numa altura em que os sistemas de ensino se estão a reformular. As abordagens construtivistas e co-construtivistas mostram aos alunos e professores que são ativos na aprendizagem e no desenvolvimento de estratégias para a eficiência da mesma. 0 portefólio de aprendizagem é congruente com as crenças particulares sobre a aprendizagem eficaz e as crenças sobre a eficácia do desenvolvimento profissional (KLENOWSKI; ASKEW; CARNELL, 2006).

Podemos dizer que a utilidade desta ferramenta é comprovada por quatro grandes aspectos: 1) proporciona uma abordagem construtiva do conhecimento, favorecendo a aprendizagem autorregulada; 2) a aprendizagem depende da capacidade do sujeito para refletir sobre os seus objetivos e estratégias de aprendizagem; 3) a competência e orientação estandardizada na formação de professores e 4) a reflexão contínua e documentada da experiência profissional (IMHOF; PICARD, 2009).

\section{Conclusão}

Nos últimos anos, tem havido esforços significativos para mudar o processo de formação de professores, principalmente a partir de programas que procuram ultrapassar o trabalho das omnipresentes competências pedagógicas, técnicas e comportamentais. É largamente aceite que aprender a ensinar é tanto uma questão de cultivar determinadas disposições e sensibilidades, como um acumular de ferramentas pedagógicas (ZEICHNER; LISTON, 1987; REICHERT, 1990; ZEICHNER; TABACHNI, 1991; FENSTERMACHER, 1992; TOM, 1997; citados por DARLING, 2001). Por outro lado, avaliar professores requer que se tenha em atenção competências básicas em áreas específicas, mas também que se consiga diferenciar os professores com base nas competências que possuem. A introdução da avaliação por portefólios permitiu uma melhor distinção na avaliação dos professores (TUCKER et al., 2003). Dependendo do seu conteúdo e modo de apresentação (em papel ou em formato digital), esta ferramenta deve fazer jus ao facto de que o ensino é uma atividade complexa e de que os comportamentos dos professores estão vinculados às suas cognições e ao contexto de ensino (LYONS, 1998). 
Embora não existam muitos casos de professores considerados não aptos, esta nova ferramenta é bastante útil para que se consiga discriminar mais facilmente professores competentes de professores excepcionais. Ainda assim, não se pode afirmar que os portefólios são, por si só, responsáveis pela distinção entre os professores que alcançam as expectativas e aqueles que as ultrapassam, tal como pelo cada vez maior número de professores certificados. No entanto, pode-se dizer que têm contribuído para um sistema de avaliação que promove e reconhece a excelência profissional (TUCKER et al., 2003).

A aplicação do portefólio como estratégia de avaliação requer uma profunda mudança na concepção que os futuros professores têm sobre a sua avaliação e seu desenvolvimento profissional. Em muitos casos, ainda predomina na mente destes um sistema de avaliação que não ultrapassa a mera "prestação de contas" ou da confırmação de realizações, fugindo à análise do desenvolvimento do processo de ensino-aprendizagem (AZCÁRATE; CARDEÑOSO; SERRADÓ, 2005). A introdução destas metodologias de formação e avaliação deve encorajar os professores a participar regularmente de atividades similares, para que possam refletir sobre as suas práticas pedagógicas, identificar as suas qualidades/fraquezas e determinar áreas fulcrais de mudança, que acabam por ter um impacto direto e uma influência significativa sobre as próprias aprendizagens dos seus alunos (ATTINELLO; LARE; WATERS, 2006).

Atendendo aos quatro aspectos anteriormente citados por Imhof e Picard (2009), podemos, em resumo, tecer algumas considerações:

Em primeiro lugar, a análise do panorama europeu do uso do portefólio aqui referida nos permite salientar a sua importância como método de avaliação docente, favorecendo uma construção multidimensional e interdisciplinar. Queremos com isto dizer que a construção desta ferramenta, em qualquer fase da carreira docente, deve partir das perspectivas do próprio docente, mas também dos seus colegas de trabalho e mesmo dos seus alunos, pois todos podem contribuir com críticas construtivas para um ensino cada vez melhor (independentemente das dificuldades de cada aluno). Um bom professor não pode centrar o seu modelo de ensino numa única teoria, deve ser conhecedor de várias e criar um modelo próprio, capaz de satisfazer as necessidades de todos e de cada um, criando um ambiente onde se senta capaz e demonstre confiança/segurança nas suas competências. Deve ser capaz de se autorregular.

Em segundo lugar, ao construir um portefólio para avaliação, o professor deve fazê-lo de modo que todos possam acompanhar o seu percurso de crescimento profissional, perceber onde surgem as mudanças e as confirmações de paradigma, ou seja, traduzir em produtos a aprendizagem que fez ao longo do tempo e que está estabelecida na sua atitude e comportamento. Por outro lado, este processo criativo deve salientar os processos críticos que levaram à mudança interna (por meio das reflexões) e à alteração/ajuste das estratégias de ensino e aprendizagem, em caso de necessidade.

Em terceiro lugar, ainda que o portefólio de avaliação seja um produto pessoal e único, não deve ser descurada a necessidade dos pontos comuns/obrigatórios a todos os docentes e que se constituem como a base de um sistema justo e equitativo de avaliação que permita fazer diferenciações justas.

Finalmente e considerando que o professor atualiza regularmente o seu portefólio, mantendo uma visão temporal profunda do seu trabalho, podemos dizer que este instrumento permite uma avaliação pontual (o trabalho de um ano letivo, a determinada altura), mas também uma avaliação longitudinal, patenteando o desenvolvimento e a evolução do professor ao longo de toda a sua vida pessoal e profissional.

Ainda que o uso do portefólio se esteja a tornar numa ferramenta de avaliação com cada vez mais adeptos e utilizada pelas escolas para diversos fins, não podemos negligenciar os aspectos mais individuais deste 
processo. Ao ser uma ferramenta de construção individual, não existe uma comparação entre as técnicas de ensino dos vários colegas, nem uma discussão das metodologias a utilizar para conseguir chegar a todos os alunos, o que leva a que os erros que se cometem sejam repetidos mais vezes, ou que se insista na utilização de estratégias menos adequadas. Por outro lado, para que o portefólio seja uma ferramenta com efetiva validade, é importante, por exemplo, que os professores da mesma área científica se reúnam com frequência para discutir entre si os objetivos pedagógicos a atingir, a adequação de instrumentos e estratégias e para que possam aprender não só com as próprias falhas (para as quais alguém terá de os alertar), mas também com os erros dos seus colegas. De nada serve um feedback constantemente positivo e sobre as boas práticas já instituídas. É com um feedback negativo que podemos incrementar a qualidade do nosso trabalho, pois este nos oferece a oportunidade de pensar e reformular aquilo que não está a funcionar. Não interessa, nem terá grande valor, refletir por refletir ou "fazer porque tem de ser". É preciso a partilha entre colegas e é a reflexão dessa partilha e a perspectiva que cada um tem sobre si e o seu desenvolvimento pessoal e profissional que permitem a elaboração intencional e conscienciosa de um portefólio.

Espera-se que o uso do portefólio como ferramenta de desenvolvimento e avaliação profissional deixe de ser exceção e se transforme numa prática generalizada, justificada pelas suas potencialidades (SANTOS, 2005). Perante tudo o que foi descrito, podemos afirmar que o uso do portefólio acarreta importantes implicações educativas para o futuro, embora ainda muito esteja por fazer. Nesse sentido, é importante estudar de que forma professores de diferentes áreas e de diferentes graus de ensino encaram esse tipo de avaliação, bem como compreender quais as alterações que o sistema de formação e de avaliação docente tem de sofrer para que a adoção desta nova ferramenta seja eficaz.

0 portefólio é um instrumento importante que deve estar inserido dentro desse novo modelo avaliativo, permitindo aos docentes uma reflexão sobre a sua prática educativa e o alcance dos seus objetivos. Para que isso seja possível, é imprescindível um trabalho colaborativo entre professores/alunos, promotor da performance de ambos. Importa não esquecer que, no futuro, o uso do portefólio só fará sentido se integrado num sistema de formação/avaliação holístico, onde coexistam outros meios e instrumentos que tornem efetivo esse processo. Existe ainda um longo caminho a percorrer, mas todos esses pequenos passos têm sido marcos importantes na construção de um futuro mais promissor. Como diz Craig (2003), ilustrando o estado de desenvolvimento desta questão: "Changes... there are no endings just new beginnings” (p. 133). 


\section{Referências}

ALBERTINO, Fátima Maria; SOUZA, Nádia Aparecida. Avaliação da aprendizagem: o portfólio como auxiliar na construção de um profissional reflexivo. Estudos em Avaliação Educacional, n. 29, p. 169-189, 2004.

ALMEIDA, Patrícia Cristina; BIAJONE, Jefferson. Saberes docentes e formação inicial de professores: implicações e desafios para as propostas de formação. Educação e Pesquisa. v. 33, n. 2, p. 281-295, 2007.

ALVES, Palmira. 0 portefólio: instrumento de avaliação de uma disciplina na Universidade - Estudo de Caso. In: SILVA, Bento D.; ALMEIDA, Leandro S. (Eds.). Actas do VII Congresso Galaico-Português de Psicopedagogia. Braga: CIEd/Universidade do Minho, p. 1113-1125, 2005.

ALVES, Ana Paula; GOMES, Maria João. E-portefólios: um estudo de caso no ensino da matemática. In: BARCA, Alfonso et al. (Eds.). Libro de Actas do Congreso Internacional Galego-Portugués de Psicopedagoxia. Corunha: Universidade da Corunha, 2007, p. 1035-1046.

ATHANASES, Steven Z. Teachers' reports of the effects of preparing portfolios of literacy instruction. The Elementary School Journal, v. 94, n. 4, p. 421-439, 1994.

ATTINELLO, Jacqueline; LARE, Douglas; WATERS, Faith. The value of teacher portfolios for evaluation and professional growth. NASSP Bulletin. v. 90, n. 2, p. 132-152, 2006.

AZCÁRATE, Pilar; CARDEÑOSO, José Maria; SERRADÓ, Anna. The learning portfolio as an assessment strategy in teacher education. Proceedings of the Congress of the European Society for Research in Mathematics Education - CERME 4, Barcelona, $p$. 1430-1439, 2005. CD-ROM

BIAZZI, Maria Fernanda Rocha Tabacow. Avaliação da aprendizagem e formação do professor: concepções e experiências. Campinas, 2006. Dissertação de mestrado em Educação, Pontifícia Universidade Católica de Campinas.

BIRENBAUM, Menucha. Assessment 2000: towards a pluralistic approach to assessment. In: ; DOCHY, Filip J. R. C. (Eds.). Alternatives in assessment of achievements, learning processes and prior knowledge. Boston, MA: Kluwer Academic Press, 1996, p. 3-29.

BORKO, Hilda et al. Student teaching portfolios: a tool for promoting reflective practice. Journal of Teaching Education, v. 48, n. 5, p. 347-357, 1997.

BULLOCK, Ann Adams; HAWK, Parmalee. Developing a teaching portfolio. Columbus, OH: Merrill, 2001.

CHIAVENATO, Idalberto. Gestão de pessoas: o novo papel dos recursos humanos nas organizações. 2. ed. Rio de Janeiro: Elsevier, 2004.

CRAIG, Cheryl. School portfolio development: a teacher knowledge approach. Journal of Teacher Education, v. 54, n. 2, p. 122$134,2003$.

CHRISTIANSEN, Bent; WALTER, Gerd. Task and activity. In: CHRISTIANSEN, Bent; HOWSON, Albert G.; OTTE, Michael (Eds.). Perspectives on mathematics education. Doedrecht: D. Reidel, 1986, p. 243-307.

DANIELSON, Charlotte; McGREAL, Thomas L. Teacher evaluation to enhance professional practice. Princeton, NJ: Educational Testing Service, 2000.

DARLING-HAMMOND, Linda; SYNDER, Jon. Authentic assessment of teaching in context. Teaching and Teacher Education, v. 16, n. 5-6, p. 523-545, 2000.

DARLING, Linda Farr. Portfolio as practice: the narratives of emerging teachers. Teaching and Teacher Education, v. 17, n. 1, p. 107-121, 2001.

DELANDSHERE, Ginette; ARENS, Sheila A. Examining the quality of the evidence in preservice teacher portfolios. Journal of Teacher Education, v. 54, n. 1, p. 57-73, 2003. 
FORTE, Ana M. B. P. X. Formação contínua: contributos para o desenvolvimento profissional e para a (re)construção da(s) identidade(s) dos professores do 1. ${ }^{\circ} \mathrm{CEB}$. Braga, 2005. Dissertação de mestrado em Educação, especialização em Desenvolvimento Curricular, Universidade do Minho - Instituto de Educação e Psicologia.

FRYER-EDWARDS, Kelly; PINSKY, Linda E.; ROBINS, Lynne. The use of portfolios to assess professionalism. In: STERN, David Ed.). Measuring medical professionalism. New York: Oxford University Press, 2006, p. 213-234.

GOMES, Maria João. Portefólios digitais: revisitando os princípios e renovando as práticas. In: MOREIRA, António et al. Actas do VII Colóquio sobre Questões Curriculares - COLÓQUIO LUSO-BRASILEIRO SOBRE QUESTÕES CURRICULARES, 3., 2006, Braga. Universidade do Minho, 2006, p. 295-306.

. Educational potential of e-portfolios: from student learning earning to teacher professional development. In: COSTA, Fernando Albuquerque; LARANJEIRO, Maria Adelino (Orgs.). E-portfolio in education: practices and reflections. Coimbra: Associação de Professores de Sintra, 2008, p. 13-20.

GRIFFITHS, Vivienne. The reflective dimension in teacher education. International Journal of Educational Research, v. 33, n. 5, p. 539-555, 2000.

GREEN, James E.; SMYSER, Sheryl 0. Changing conceptions about teaching: The use of portfolios with pre-service teachers. Teacher Education Quarterly, v. 22, n. 2, p. 43-53, 1995.

HAUGE, Trond E. Portfolios and ICT as means of professional learning in teacher education. Studies in Educational Evaluation, v. 32, n. 1, p. 23-36, 2006.

IMHOF, Margarte; PICARD, Christin. Views on using portfolio in teacher education. Teaching and Teacher Education, v. 25, n. 1, p. 149-154, 2009.

KLENOWSKI, Val; ASKEW, Sue; CARNELL, Eileen. Portfolios for learning, assessment and professional development in higher education. Assessment \& Evaluation in Higher Education, v. 31, n. 3, p. 267-286, 2006.

KORTHAGEN, Fred. Linking practice and theory: the pedagogy of realistic teacher education. Mahwah, $\mathrm{NJ}$ : Lawrence Erlbaum Associates, 2001.

LEAL, Leonor Cunha. Portfolio ou pasta do aluno. Educação e Matemática, n. 42, p. 11-12, 1997.

LEITÃO, Álvaro; ALARCÃO, Isabel. Para uma nova cultura profissional: Uma abordagem da complexidade na formação inicial de professores do $1^{\circ}$ CEB. Revista Portuguesa de Educação, v. 19, n. 2, p. 51-84, 2006.

LORENZO, George; ITTELSON, John. An overview of E-portfolios. Retrieved September 25, 2009. Disponível em: http://net. educause.edu/ir/library/pdf/ELI3001.pdf, 2005.

LOUGHRAN, John; CORRIGAN, Deborah. Teaching portfolios: a strategy for developing learning and teaching in pre-service education. Teaching and Teacher Education, v. 11, n. 6, p. 565-577, 1995.

LOVE, Douglas; MCKEAN, Gerry; GATHERCOAL, Paul. Portfolios to webfolios and beyond: levels of maturation. Educause Quarterly, v. 27, n. 2, p. 24-37, 2004.

LYONS, Nona (Ed.). With portfolio in hand: Validating the new teacher professionalism. New York: Teachers College Press, 1998. MANSVELDER-LONGAYROUX, Désirée.; BElJAARD, Douwe; VERLOOP, Nico. The portfolio as a tool for stimulating reflection by student teachers. Teaching and Teacher Education, v. 23, n. 1, p. 47-62, 2007.

MARTINELLO, Marian; COOK, Gillian. Indagación interdisciplinaria en la enseñanza y el aprendizaje. Barcelona: Gedisa, 2001.

McLAUGHLIN, Maureen; VOGT, Mary Ellen. Portfolio assessment for in service teachers: a collaborative model. In: McLAUGHLIN, Maureen et al. (Eds.). Professional portfolio models: applications in education. Norwood, MA: Christopher-Gordon Publishers, 1998, p. 1-76.

MEEUS, Wil; PETEGEM, Peter Van; ENGELS, Nadine. Validity and reliability of portfolio assessment in pre-service teacher education. Assessment \& Evaluation in Higher Education, v. 34, n. 4, p. 401-413, 2009. 
OUELLETT, Mathew. Your teaching portfolio: strategies for initiating and documenting growth and development. Journal of Management Education, v. 31, n. 3, p. 421-433, 2007.

PECHEONE, Raymond et al. Performance assessment and electronic portfolios: their effect on teacher learning and education. The Clearing House, v. 78, n. 4, p. 164-176, 2005.

PEREIRA, Carla; CRUZ, Eduardo; LUCENA, Aldina. Portefólio profissional - um instrumento para o desenvolvimento profissional contínuo. EssFisiOnline, v. 2, n. 3, p. 70-89, 2006.

PETERSON, Kenneth D. Teacher evaluation: a comprehensive guide to new directions and practices. Thousand Oaks, CA: Corwin Press, 2000.

REIFSCHEIDER, Marina Becker. Considerações sobre avaliação de desempenho. Ensaio - Avaliação e Políticas Públicas em Educação, v. 16, n. 58, p. 47-58, 2008.

RIBAS, Mariná H; MARTINS, Rosilda B.; LUPORINI, Teresa J. A formação contínua como possibilidade de afirmação da identidade profissional de professores de história. Olhar de Professor, v. 4, n. 1, p. 79-92, 2001.

ROLHEISER, Carol; SCHWARTZ, Susan. Pre-service portfolios: a base for professional growth. Canadian Journal of Education, v. 26, n. 3, p. 283-300, 2001.

SALEND, Spencer J. Creating your own professional portfolio. Intervention in School and Clinic, v. 36, n. 4, p. 195-201, 2001.

SANTOS, Leonor. The portfolio in teacher education. Proceedings of the Congress of the European Society for Research in Mathematics Education - CERME 4, Barcelona, p. 1579-1587, 2005. CD-ROM

SMITH, Kari; TILLEMA, Harm. Clarifying different types of portfolio use. Assessment \& Evaluation in Higher Education, v. 28, n. 6, p. 625-648, 2003.

SAWYER, Lynn. Revamping a teacher evaluation system. Educational Leadership, v. 58, n. 5, p. 44-47, 2001.

SELDIN, Peter (Ed.). The teaching portfolio: a practical guide to improved performance and promotion/tenure decisions. 3rd ed. Bolton, MA: Anker, 2004

TILLEMA, Harm. Design and validity of a portfolio instrument for professional training. Studies in Educational Evaluation, v. 24, n. 3, p. 263-278, 1998.

TUCKER, Pamela; STRONGE, James; GAREIS, Christopher. Handbook on teacher portfolios for evaluation and professional development. Larchmont, New York: Eye on Education, 2002.

TUCKER, Pamela et al. The efficacy of portfolios for teacher evaluation and professional development: Do they make a difference? Educational Administration Quarterly, v. 39, n. 5, p. 572-602, 2003.

VAN DER SCHAAF, Marieke F; STOKKING, Karel M. Developing and validating a design for teacher portfolio assessment. Assessment \& Evaluation in Higher Education, v. 33, n. 3, p. 245-262, 2008.

WINSOR, Pamela J. T; ELLEFSON, Bryan A. Professional portfolios in teacher education: An exploration of their value and potential. The Teacher Educator, v. 31, n. 1, p. 68-74, 1995.

WOLF, Kenneth; LICHTENSTEIN, Gary; STEVENSON, Cynthia. Portfolios in teacher evaluation. In: STRONGE, James H. (Ed.). Evaluating teaching: a guide to thinking and best practice. Thousand Oaks, CA: Corwin Press, 1997, p. 193-214.

ZEICHNER, Ken; WRAY, Susan. The teaching portfolio in US teacher education programs: what we know and what we need to know. Teaching and Teacher Education, v. 17, n. 5, p. 613-621, 2001. 
ZEPEDA, Sally J. Linking portfolio development to clinical supervision: a case study. Journal of Curriculum and Supervision, v. 18, n. 1, p. 83-102, 2002

Recebido em: 11.03.2010

Aprovado em: 15.03 .2011

João Silva é licenciado em Psicologia pela Universidade de Évora (Portugal), é atualmente aluno do mestrado em Psicologia da Educação na mesma instituição.

Nicole Rebelo é licenciada em Psicologia pela Universidade de Évora (Portugal), é atualmente aluna de mestrado em Psicologia da Educação na mesma instituição. E-mail: nicolesantosrebelo@gmail.com.

Patrícia Mendes é licenciada em Psicologia pela Universidade de Évora (Portugal), é atualmente aluna do mestrado em Psicologia da Educação na mesma instituição. E-mail: patriciatrindademendes@gmail.com.

Adelinda Candeias é doutorada em Psicologia e professora auxiliar pela e na Universidade de Évora, onde assume também o papel de investigadora responsável por projetos europeus, como IRIS e DAFFODIL. E-mail: aac@uevora.pt. 